\title{
Single-Molecule Observation of the Intermediates in a Catalytic Cycle
}

\author{
William J. Ramsay, Nicholas A. W. Bell, Yujia Qing, Hagan Bayley* \\ University of Oxford, Chemistry Research Laboratory, Oxford, OX1 3TA, UK
}

\begin{abstract}
The development of catalysts benefits from knowledge of the intermediate steps that accelerate the transformations of substrates into products. However, key transient species are often hidden in ensemble measurements. Here, we show that a protein nanoreactor can sample the intermediate steps in a catalytic cycle by the continuous single-molecule observation of a stoichiometric reaction in solution. By monitoring changes in the flow of ionic current through an $\alpha$-hemolysin protein pore, we observed three intermediate metal-ligand complexes in a gold(I)catalysed reaction that converts an acetylenic acid to an enol lactone, revealing a transitional coordination complex that had been previously unobserved. A kinetic isotope effect helped assign the various metal-ligand species. Measurements of the lifetimes of the intermediates allowed a full kinetic analysis of the metal-catalysed reaction cycle.
\end{abstract}

\section{INTRODUCTION}

Chemical reactions catalysed by metals provide access to valuable pharmaceuticals ${ }^{1}$ and fine chemicals. ${ }^{2}$ The control over bond-breaking and bond-forming processes during metal-catalysed reactions $^{3}$ requires awareness of the intermediate metal-ligand species ${ }^{4-5}$ that mediate the conversion of substrates into products. ${ }^{6}$ This critical information is restricted by the limited number of techniques to monitor transient species continuously with molecular resolution. ${ }^{7-11}$ Although single-molecule fluorescence microscopy has enabled the investigation of the initiation dynamics of a surface-supported palladium catalyst, ${ }^{12-14}$ the resolution of the multiple kinetic steps involved in a catalytic cycle remains elusive. The nanoreactor approach used here is a versatile technique to observe the kinetics of transient intermediates at the single-molecule level.

The staphylococcal $\alpha$-hemolysin $(\alpha \mathrm{HL})$ transmembrane pore (Figure $1 \mathrm{a})^{15}$ has been used as a nanoreactor ${ }^{16}$ to monitor a variety of chemistries at the single-molecule level, including metal ion chelation, ${ }^{17}$ the detection of metal-coordinating neurotransmitters, ${ }^{18}$ a kinetic isotope effect, ${ }^{19-20}$ $\mathrm{Cu}(\mathrm{I})$-catalyzed azide-alkyne cycloaddition, ${ }^{21}$ and the continuous, stochastic movement of a smallmolecule walker along a five-foothold track. ${ }^{22}$ Here, we use the $\alpha H L$ nanoreactor to examine a metal-catalysed reaction (Figure 1b). The lumen of an $\alpha \mathrm{HL}$ pore was genetically engineered to accommodate the binding of a single, catalytically active $\mathrm{Au}^{\mathrm{I}}$ metal ion, which binds to alkyne substrates (Figure 1c), and can catalytically cyclise acetylenic acids to enol lactones (Figure 1d). ${ }^{23-}$ 25 

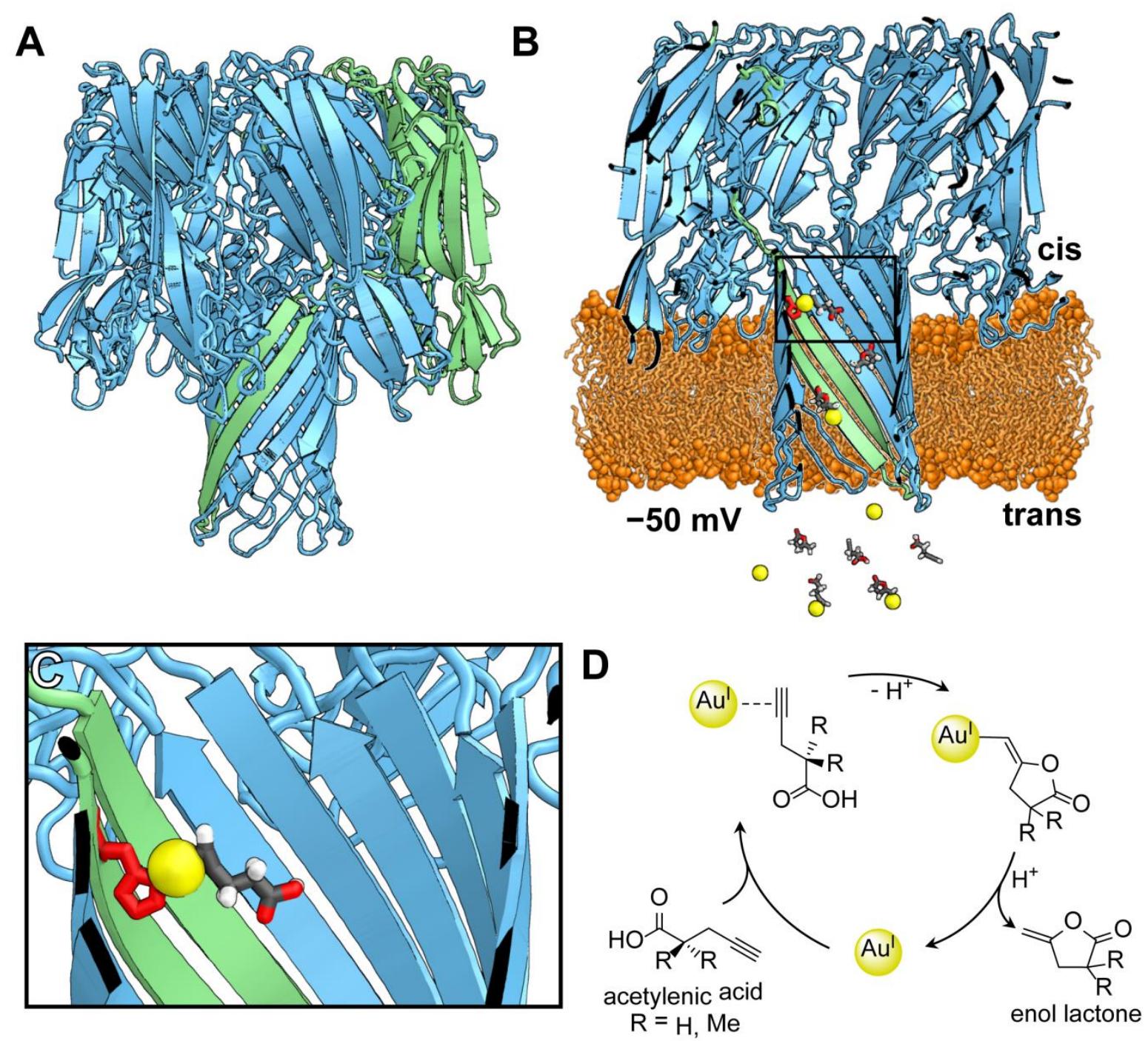

Figure 1. The $\mathrm{P}_{\mathrm{H}} \alpha \mathrm{HL}$ pore: a nanoreactor for the investigation of $\mathrm{Au}^{\mathrm{I}}$ catalysis. (a) WT $\alpha H L$ (PDB code $7 \mathrm{AHL}$ ) is a mushroom-shaped transmembrane protein pore comprising seven identical subunits. A side view of the ribbon structure shown with one of the subunits highlighted in green. (b) A sagittal section of the engineered $\alpha \mathrm{HL}$ pore, $\mathrm{P}_{\mathrm{H}}$, embedded in a planar lipid bilayer (orange) for single-channel electrical recording. $\mathrm{P}_{\mathrm{H}}$ contains one subunit with a histidine substitution at position 145 (red in stick representation). The side chain of His-145 points into the lumen of the transmembrane $\beta$ barrel and can coordinate metal-ligand complexes from solution, entering from the trans compartment. (c) An expanded view around His-145, with bound 4-pentynoic acid: $\mathrm{Au}^{\mathrm{I}}$ (yellow sphere), 4-pentynoic acid (stick representation: carbon, grey; hydrogen, white; oxygen, red). (d) The proposed catalytic cycle for transformation of an acetylenic acid to an enol lactone.

In our study, the modified $\alpha H L$ pore serves as a sensing platform; the catalytic transformation of acetylenic acids predominantly occurs in solution, while the pore samples the intermediate metal-ligand species that are involved in the reaction and records the interconversions of each intermediate. Continuous monitoring over the course of the reaction allows the assembly of information connecting catalytic steps and thereby the construction of a catalytic cycle in accord with our single-molecule observations. Our approach suggests a general method to follow metalcatalysed aqueous reactions. 


\section{RESULTS \& DISCUSSION}

\section{Gold(I) binding to the synthetic pore.}

Before investigating the $\mathrm{Au}^{\mathrm{I}}$ catalysed reaction, we examined the binding of $\mathrm{Au}^{\mathrm{I}}$ and $\mathrm{Au}^{\mathrm{I}}$ alkyne complexes to the nanopore. We used a histidine-containing $\alpha \mathrm{HL}$ pore to determine the binding kinetics of $\mathrm{Au}^{\mathrm{I}}$ with an imidazole group at $21 \pm 1{ }^{\circ} \mathrm{C}$ (Figure 2a). The same pore was subsequently used to study $\mathrm{Au}^{\mathrm{I}}$ catalysis. A mutant $\alpha \mathrm{HL}$ monomer, T145H, was assembled together with wild-type (WT) subunits, and the heteroheptameric pore $(\mathrm{WT})_{6}(\mathrm{~T} 145 \mathrm{H})_{1}$ (referred to as $\left.\mathrm{P}_{\mathrm{H}}\right)$ was purified by SDS-polyacrylamide gel electrophoresis (Supplementary Section 1.2, Figure S1). The histidine substitution at position 145 in $\mathrm{P}_{\mathrm{H}}$ orientates the imidazole side-chain into the lumen of the $\beta$ barrel, where it can coordinate to a single $\mathrm{Au}^{\mathrm{I}}$ cation (none of the natural His residues in the protein are in the conductive pathway, Figure S2). The amplitude of the metal-binding events was enhanced by positioning the coordinating ligand near the pore constriction. ${ }^{26} \mathrm{P}_{\mathrm{H}}$ was characterised by current recording in planar lipid bilayers and carried a single-channel current of $-76.6 \pm 2.1 \mathrm{pA}$ at $-50 \mathrm{mV}$ in $2 \mathrm{M} \mathrm{KCl}, 10 \mathrm{mM}$ 2-( $N$-morpholino)ethanesulfonic acid (MES), $\mathrm{pH}$ $6.1(n=25$; Table S1). The addition of gold(I) chloride to the trans compartment resulted in the fluctuation of the ionic current between two discrete levels separated by $\Delta I=1.10 \pm 0.07 \mathrm{pA}$ (Figure $2 \mathrm{~b}$ ), where $\Delta I$ is the difference between the current carried by the unoccupied pore $\left(\mathrm{P}_{\mathrm{H}}\right)$ and that of the pore with bound $\mathrm{Au}^{\mathrm{I}}\left(\mathrm{P}_{\mathrm{H}} \cdot \mathrm{Au}^{\mathrm{I}}\right)$, i.e. metal binding results in an increase in the unitary conductance of the pore. ${ }^{18}$ Although metal binding to modified $\alpha \mathrm{HL}$ pores has been observed to both induce and block the flow of current, the subtle reasons behind this phenomenon have yet to be elucidated. The dominant gold species in $2 \mathrm{M} \mathrm{KCl}$ at $\mathrm{pH} 6.1$ and $21 \pm 1^{\circ} \mathrm{C}$ in the binding experiments is the linear molecule $\mathrm{Au}^{\mathrm{I}} \mathrm{Cl}_{2}{ }^{-}$, as the gold concentrations $(\leq 5 \mu \mathrm{M})$ are well below the isoactivity boundary between $\mathrm{Au}^{\mathrm{I}} \mathrm{Cl}_{2}{ }^{-}$and $\mathrm{Au}^{\mathrm{III}} \mathrm{Cl}_{4}{ }^{-}$and disproportionation to $\mathrm{Au}{ }^{\mathrm{III}}$ and $\mathrm{Au}^{0}$ is negligible. ${ }^{27-28}$ The events associated with $\mathrm{Au}^{\mathrm{I}}$ binding had a mean lifetime $\left(\tau_{\mathrm{off}}\right)$ of $2.1 \pm 0.2 \mathrm{~s}$ and were not seen with $\mathrm{WT}_{7}$ pores (Figure S11). By assuming that the $\mathrm{Au}^{\mathrm{I}} \mathrm{Cl}_{2}{ }^{-}$concentration inside the pore equals that in solution, ${ }^{16}$ we performed a kinetic analysis of the events, and deduced that the histidine residue and $\mathrm{Au}^{\mathrm{I}}$ reversibly form a binary complex (Figure 2c, top). The reciprocal of the mean inter-event interval $\left(\tau_{\mathrm{on}}\right)$ is proportional to the $\mathrm{Au}^{\mathrm{I}} \mathrm{Cl}_{2}{ }^{-}$concentration, which is consistent with a bimolecular interaction for which $1 / \tau_{\text {on }}=k_{\text {on }}\left[\mathrm{Au}^{\mathrm{I}} \mathrm{Cl}_{2}{ }^{-}\right]$. In contrast, a plot of the reciprocal of the mean lifetime of the complex $\left(\tau_{\text {off }}\right)$ versus the $\mathrm{Au}^{\mathrm{I}} \mathrm{Cl}_{2}{ }^{-}$concentration has a near zero slope (Figure $2 \mathrm{c}$, bottom), which is consistent with a unimolecular dissociation mechanism $\left(1 / \tau_{\mathrm{off}}=k_{\mathrm{off}}\right)$. The values of $\tau_{\text {on }}$ and $\tau_{\text {off }}$ were determined by fitting dwell-time histograms for each $\mathrm{Au}^{\mathrm{I}} \mathrm{Cl}_{2}{ }^{-}$ concentration to single exponential functions. The forward $\left(k_{\mathrm{on}}=1.52 \pm 0.05 \times 10^{6} \mathrm{M}^{-1} \mathrm{~s}^{-1}\right)$ and reverse $\left(k_{\mathrm{off}}=0.49 \pm 0.05 \mathrm{~s}^{-1}\right)$ rate constants derived from the $\tau$ values yield an equilibrium 
association constant of $\mathrm{Au}^{\mathrm{I}}$ to imidazole of $K_{\mathrm{a}}=3.1 \pm 0.3 \times 10^{6} \mathrm{M}^{-1}(n=4$, independent experiments).
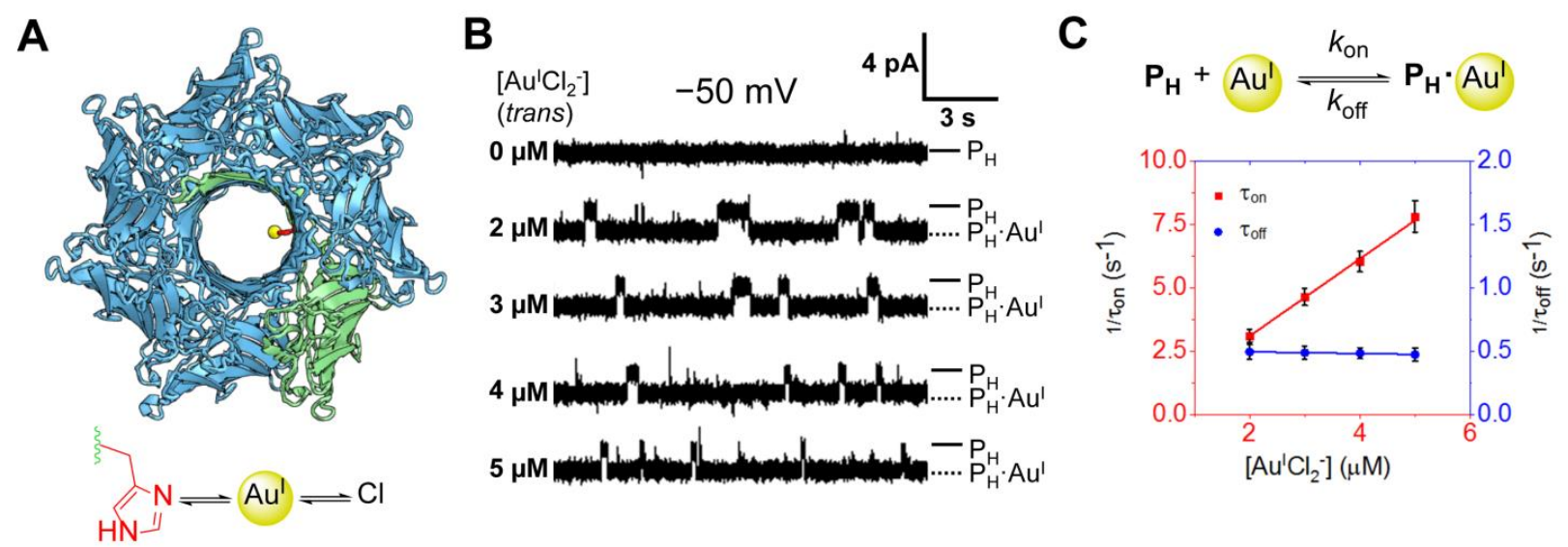

Figure 2. The $\mathrm{P}_{\mathrm{H}}$ pore binds $\mathrm{Au}^{\mathrm{I}}$. (a) Ribbon representation of the $\mathrm{P}_{\mathrm{H}}$ pore viewed from the bottom of the $\beta$ barrel. The single histidine side chain (red) binds $\mathrm{Au}^{\mathrm{I}}$ (yellow sphere) reversibly. (b) Single-channel recordings at $-50 \mathrm{mV}$ with 2 $\mathrm{M} \mathrm{KCl}, 10 \mathrm{mM}$ MES (pH 6.1) in both compartments, and 0 to $5 \mu \mathrm{M} \mathrm{Au}{ }^{\mathrm{I}} \mathrm{Cl}$ in the trans compartment. The two current levels correspond to the unoccupied pore $\left(\mathrm{P}_{\mathrm{H}}\right)$ and to the pore with $\mathrm{Au}^{\mathrm{I}} \mathrm{Cl}_{2}{ }^{-}$bound to the histidine residue $\left(\mathrm{P}_{\mathrm{H}} \cdot \mathrm{Au}^{\mathrm{I}}\right)$. $(\mathbf{c})$ Proposed kinetic scheme describing $\mathrm{Au}^{\mathrm{I}}$ binding to the $\mathrm{P}_{\mathrm{H}}$ pore and plots of the reciprocals of the mean inter-event intervals $\left(\tau_{\text {on }}\right)$ and the dwell times of $\mathrm{Au}^{\mathrm{I}}\left(\tau_{\text {off }}\right)$ versus the $\mathrm{Au}^{\mathrm{I}} \mathrm{Cl}_{2}^{-}$concentration.

We also prepared the phosphine-coordinated Au-complex chloro(tris(2carboxyethyl)phosphine) gold(I) ( $\left.\mathrm{u}^{\mathrm{I}}(\mathrm{tcep}) \mathrm{Cl}\right)$ in situ by mixing chloro(tetrahydrothiophene) gold(I) ( $\left.\mathrm{Au}^{\mathrm{I}}(\mathrm{tht}) \mathrm{Cl}\right)$ with TCEP (tris(2-carboxyethyl)phosphine) (Supplementary Section 1.4). Phosphine ligated $\mathrm{Au}^{\mathrm{I}}$-complexes are commonly used as catalysts to activate alkenes and alkynes, ${ }^{29-31}$ where the phosphine ligand engenders solubility to a discrete $\mathrm{Au}^{\mathrm{I}}$ complex. In order to follow the $\mathrm{Au}^{\mathrm{I}}$-catalysed cyclisation of acetylenic acids at the single-molecule level, we found that the use of $\mathrm{Au}^{\mathrm{I}}(\mathrm{tcep}) \mathrm{Cl}$ was a necessity (see below). Although we observed TCEP coordination to $\mathrm{Au}^{\mathrm{I}} \mathrm{Cl}_{2}{ }^{-}$in $2 \mathrm{M} \mathrm{KCl}$ solutions by ${ }^{31} \mathrm{P}\left\{{ }^{1} \mathrm{H}\right\}$ NMR spectroscopy (Figure S4), in single-molecule experiments, we did not observe blocking events consistent with the coordination of TCEP (or THT) to $\mathrm{Au}^{\mathrm{I}}$ bound to His-145 when $\mathrm{Au}^{\mathrm{I}}($ tcep)Cl was added to the trans compartment (Figures S12 and S13). Rather, we observed fluctuations in the ionic current consistent with $\mathrm{Au}^{\mathrm{I}} \mathrm{Cl}_{2}{ }^{-}$binding that occurs from the ligand exchange of $\mathrm{Au}^{\mathrm{I}}(\mathrm{tcep}) \mathrm{Cl}$ in $2 \mathrm{M} \mathrm{KCl}$ solution (Table $\mathrm{S} 2$ and Supplementary Section 2.3). Thus, although $\mathrm{Au}^{\mathrm{I}}(\mathrm{tcep}) \mathrm{Cl}$ is present in solution, we did not have to consider events associated with TCEP binding to $\mathrm{P}_{\mathrm{H}}$-bound $\mathrm{Au}^{\mathrm{I}}$ when we used $\mathrm{Au}^{\mathrm{I}}($ tcep$) \mathrm{Cl}$ in our alkyne binding and catalytic investigations. We postulate that the dwell time, $\tau_{\text {off, of TCEP bound }}$ to $\mathrm{a} \mathrm{Au}^{\mathrm{I}}$ ion bound to $\mathrm{P}_{\mathrm{H}}$ is beyond the resolution of the experiment, perhaps exacerbated by the trans influence of the imidazole coordinating group. ${ }^{32}$ 


\section{Alkyne Binding to gold(I)}

A key, first step in homogeneous $\mathrm{Au}^{\mathrm{I}}$-catalysed reactions of alkynes is the formation of $\mathrm{a} \mathrm{Au}$ alkyne $\pi$-complex, in which the alkyne binds side-on to a single $\mathrm{Au}^{\mathrm{I}}$ centre (Figure 1d). ${ }^{33-36}$ Before investigating a $\mathrm{Au}^{\mathrm{I}}$ catalysed reaction, we sought to detect this binding behaviour at the singlemolecule level. We prepared a series of alkyne esters (1 - 3; Figure 3, a to c), which can coordinate to but not react on $\mathrm{Au}^{\mathrm{I}}$, and investigated their binding behaviour to $\mathrm{Au}^{\mathrm{I}}$ and the histidine pore $\mathrm{P}_{\mathrm{H}}$. Alkyne-ester 1 and $\mathrm{Au}^{\mathrm{I}}(\mathrm{tcep}) \mathrm{Cl}$ were mixed in a 1:1 ratio and added to the trans compartment of the recording apparatus at $-50 \mathrm{mV}$ in $2 \mathrm{M} \mathrm{KCl}, 10 \mathrm{mM}$ MES, $\mathrm{pH}$ 6.1. NMR spectroscopy confirmed that these components do not react ${ }^{37}$ (Figures S14 and S15) and that the binding of the alkyne-ester to $\mathrm{Au}^{\mathrm{I}}$ (tcep)Cl is weak. ${ }^{38}$ In addition to the binding of $\mathrm{Au}^{\mathrm{I}} \mathrm{Cl}_{2}{ }^{-}$to histidine, two further reversible current blockades were observed: at $4.8 \pm 0.2 \mathrm{pA}$ (with respect to $\mathrm{P}_{\mathrm{H}}$ ) with an average lifetime of $95 \pm 4 \mathrm{~ms}$ (level 3), and at $2.2 \pm 0.2 \mathrm{pA}$ with an average lifetime of $241 \pm 30 \mathrm{~ms}$ (level 2) (Figure 3a). As we anticipated observing only one reversible current blockade from the coordination of a linear, $\mathrm{Au}^{\mathrm{I}}-\mathbf{1} \pi$-complex, the observation of two reversible current blockades prompted further investigation. These current levels were not observed with the $\mathrm{WT}_{7}$ pore.
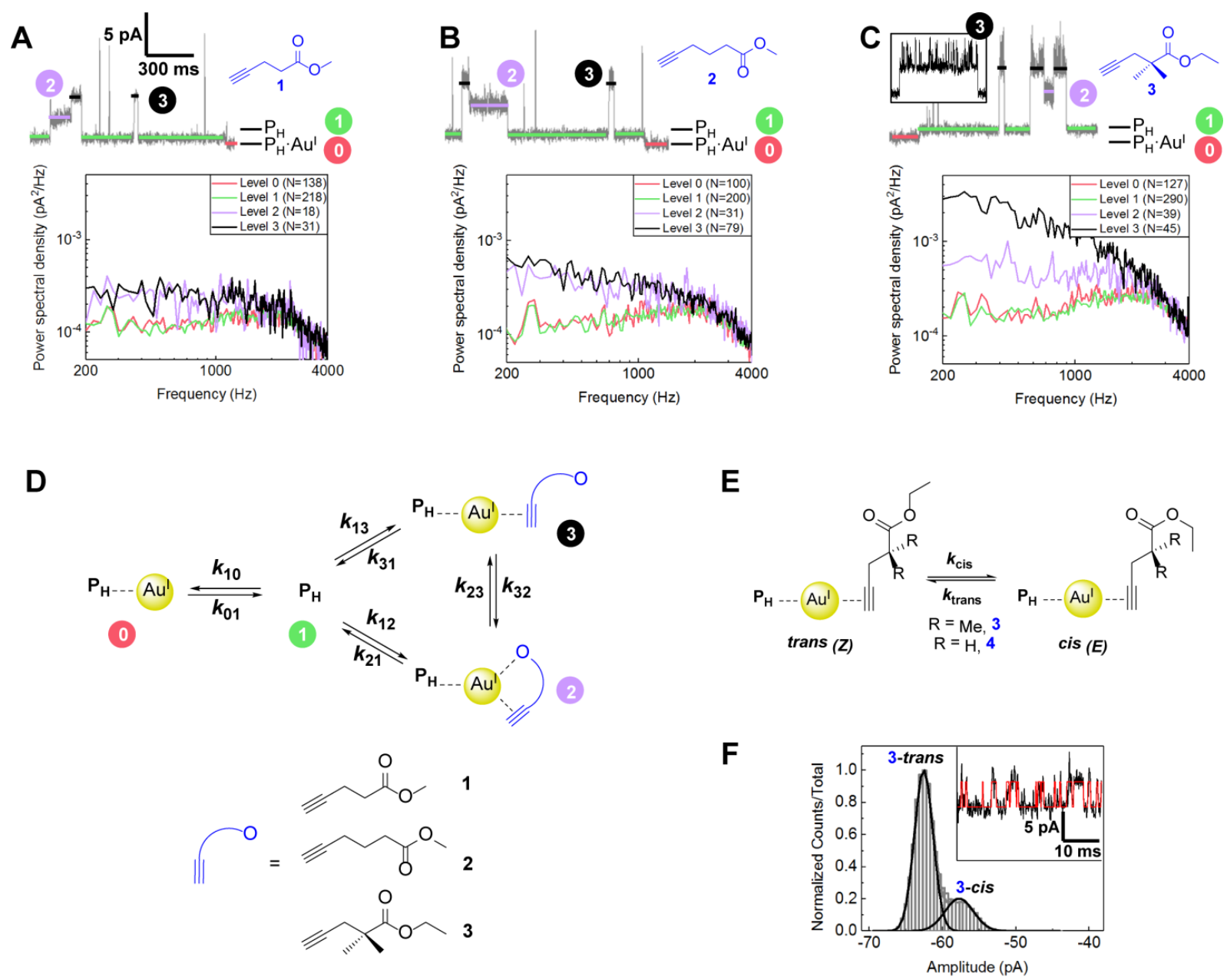

Figure 3. Detection of $\mathrm{Au}^{\mathrm{I}}$-alkyne complexes using the $\mathrm{P}_{\mathrm{H}}$ pore. $(\mathbf{a}-\mathbf{c})$ Electrical current recordings (shown in grey with an idealised trace overlaid and color coded for each level) and noise analyses for the bound states of $\mathrm{Au}{ }^{\mathrm{I}}$ - 
coordinated alkyne-esters $\mathbf{1}-\mathbf{3}$ to $\mathrm{P}_{\mathrm{H}}(\mathrm{N}=$ number of events). Inset in (c): expanded view of level 3. Concentrations $\left(\mathrm{Au}^{\mathrm{I}}(\mathrm{tcep}) \mathrm{Cl}\right.$ and alkyne-ester added in a 1:1 stoichiometry: 1, 50 $\mu \mathrm{M} ; 2,50 \mu \mathrm{M} ; \mathbf{3}, 50 \mu \mathrm{M}$. All traces are displayed on the same scale. Conditions: $2 \mathrm{M} \mathrm{KCl}, 10 \mathrm{mM} \mathrm{MES}, \mathrm{pH} 6.1,21 \pm 1{ }^{\circ} \mathrm{C}$, at an applied potential of $-50 \mathrm{mV}$. (d) $\mathrm{Kinetic}$ model used to determine the rate constants of the observed transitions. (e) Proposed kinetic scheme describing the restricted rotation of alkyne esters 3 and $\mathbf{4}$ between the trans (Z) configuration and the cis (E) configuration. (f) Allpoints histogram of the current amplitudes in level 3 observed with 3. Inset: idealised trace (QuB) of level 3 (red) overlaid on the recorded current trace (black).

Direct transitions from the unoccupied pore (level 1) to level 3 or level 2 and transitions between levels 3 and 2 were commonly observed, but transitions from the Au-occupied level (level 0$)$ to levels 3 and 2 were rarely recorded ( $<1 \%$ of the total transitions) (Figure S16). We created a four-state model to describe the observed transitions (Figure 3d). The rate constants of the transitions between each state were determined by analysing idealised current traces with Hidden Markov modelling (QUB 2.0, Buffalo University) (Table 1). The association rate from level 1 to level 2 (corresponding to rate constant $k_{12}$ ) or level 3 (rate constant $k_{13}$ ) showed a firstorder dependence on the concentration of the $\mathrm{Au}^{\mathrm{I}}-\mathbf{1}$ complex (Figure S17), while dissociation (rate constants $k_{21}$ and $k_{31}$ ) was independent of the concentration, consistent with a bimolecular interaction between $\mathrm{Au}^{\mathrm{I}}-\mathbf{1}$ and $\mathrm{P}_{\mathrm{H}}$. The transitions between levels 3 and $2\left(k_{23}\right.$ and $\left.k_{32}\right)$ were concentration independent, suggesting that level 2 and level 3 arise from rearrangement of the coordination complex. $\mathrm{As} \mathrm{Au}^{\mathrm{I}}$ is known to form three-coordinate complexes ${ }^{39}$ in addition to the more commonly observed linear, two-coordinate complexes, we tentatively assign levels 2 and 3 to two different coordination states: a linear, $\mathrm{Au}^{\mathrm{I}} \mathbf{- 1} \pi$-complex and a three-coordinate, $\mathrm{Au}^{\mathrm{I}}$ complex chelated by the alkyne and ester groups (Figure $3 \mathrm{~d}$ ). We propose the three-coordinate, $\mathrm{Au}^{\mathrm{I}}$ complex in order to account for our single-molecule observation that the transitions between level 2 and 3 are concentration independent; although this is an atypical binding motif, similar heterotopic and multidentate ligand binding to $\mathrm{Au}^{\mathrm{I}}{ }^{\text {(Refs. }}{ }^{39-40)}$ and $\mathrm{Au}{ }^{\mathrm{III}}$ (Ref. ${ }^{41)}$ have been reported. We did not observe binding of $\mathrm{Au}^{\mathrm{I}}$-ester (Figure S18) or $\mathrm{Au}^{\mathrm{I}}$-acid (Figure S19) complexes to $\mathrm{P}_{\mathrm{H}}$, indicating that coordination must be through the alkyne. Because the amplitude of the current block for an organic molecule depends approximately on how far it extends into the pore lumen, ${ }^{18}$ the chelate state was assigned to the smaller current blockade (level 2). Although this argument is the simplest and most chemically plausible, it encouraged us to investigate additional alkyne-ester binding activity to $\mathrm{P}_{\mathrm{H}}$.

The addition of a 1:1 mixture of $\mathrm{Au}^{\mathrm{I}}\left(\right.$ tcep) $\mathrm{Cl}$ and alkyne-ester 2 to the trans side of $\mathrm{P}_{\mathrm{H}}$ produced current blockades and transitions similar to those produced by $\mathrm{Au}^{\mathrm{I}} \mathbf{- 1}$ under the same experimental conditions (Figure 3b and Figure S21); $\mathbf{2}$ differs from $\mathbf{1}$ by only an additional carbon atom in the chain between the alkyne and ester group. We found that the rate constant of the transition from level 3 to level $2\left(k_{32}\right)$, which is proposed to describe the chelation of $\mathrm{Au}^{\mathrm{I}}$ by 2 to form a 7-membered ring, was slower $\left(2.9 \pm 0.2 \mathrm{~s}^{-1}\right)$ than the formation of a 6-membered ring with 
$\mathrm{Au}^{\mathrm{I}}$ and $1\left(4.4 \pm 0.4 \mathrm{~s}^{-1}\right)$ (Figure S22); similar small differences in ring-closing rates have been observed with platinum(II)-diamine chelate complexes. ${ }^{42}$ The opening of the 7 -membered ring $\left(k_{23}\right)$ formed with 2 was slightly faster $\left(8.1 \pm 0.4 \mathrm{~s}^{-1}\right)$ than the 6-membered ring with 1 $\left(6.4 \pm 0.5 \mathrm{~s}^{-1}\right)$. These results support our initial level 3 assignment as the $\mathrm{Au}$-alkyne $\pi$-complex. Further, we determined the binding kinetics of $\mathrm{Au}^{\mathrm{I}}-\mathbf{3}$ to $\mathrm{P}_{\mathrm{H}}$ (Figure 3c) (Figures S24 and S25). The dimethyl substituents of alkyne-ester 3 did not affect the rate of ring-opening $\left(k_{23}=6.4 \pm 0.3 \mathrm{~s}^{-1}\right)$, as compared with alkyne-ester $\mathbf{1}$ (which forms the same chelate ring size), but slightly retarded the rate of ring formation $\left(k_{32}=3.0 \pm 0.3 \mathrm{~s}^{-1}\right)$ as expected from the steric influence. Although the noise that arises from level 2, which is assigned as the $\mathrm{Au}^{\mathrm{I}}$-alkyne chelate complex, was similar among alkyne-esters $\mathbf{1}-\mathbf{3}$, we observed considerable noise in the amplitude of level 3 with $\mathrm{Au}^{\mathrm{I}}-\mathbf{3}$, compared to $\mathrm{Au}^{\mathrm{I}}-\mathbf{1}$ and $\mathrm{Au}^{\mathrm{I}}-\mathbf{2}$ (Figure 3, a to c, bottom). We attribute this observation to the restricted rotation of the $\sigma$-bond within the ester group, ${ }^{43}$ as it is the slowest rotating bond within the molecule (Figure 3e). By using Hidden Markov modelling (QUB 2.0, Buffalo University) to analyse the fluctuations of level 3 from $\mathrm{Au}^{\mathrm{I}}-\mathbf{3}$ as a two state system with transitions from the trans $(Z)$ configuration to the cis $(E)$ isomer (Figure $3 \mathrm{f})$, we determined $k_{\text {cis }}\left(701 \pm 24 \mathrm{~s}^{-1}\right)$ and $k_{\text {trans }}(2193$ $\left.\pm 75 \mathrm{~s}^{-1}\right)$ and calculated an $E-Z$ free energy difference $\left(\Delta G^{\circ}\right)$ of $0.52 \mathrm{kcal} \mathrm{mol}^{-1}\left(\Delta G^{\circ}=\right.$ $\left.-\mathrm{RT} \ln \left(k_{\mathrm{cis}} / k_{\text {trans }}\right)\right)$, consistent with literature values. ${ }^{44}$ We also prepared the ethyl ester of 4 pentynoic acid (4), which omits the dimethyl substituents of $\mathbf{3}$, and observed a similar fluctuation in the amplitude of level 3 (Figure S26), and found faster $k_{\text {cis }}\left(1748 \pm 131 \mathrm{~s}^{-1}\right)$ and $k_{\text {trans }}$ $\left(3274 \pm 237 \mathrm{~s}^{-1}\right)$ values, yielding a smaller $E-Z$ free energy difference of $0.37 \mathrm{kcal} \mathrm{mol}^{-1}$. This result suggests that the observed restricted rotation was a result of the ethyl ester group. The barrier to ester rotation is consistent with a linearly-coordinated, $\mathrm{Au}^{\mathrm{I}}$-alkyne $\pi$-complex to $\mathrm{P}_{\mathrm{H}}$, in support of our assignment of level 3. We also investigated the binding of tert-butyl propargyl carbonate to $\mathrm{Au}^{\mathrm{I}}$ in the presence of $\mathrm{P}_{\mathrm{H}}$, in which the tert-butyl group sterically prevents chelation. We observed only a single current blockade, consistent with the formation of a simple $\pi$-complex and not a chelate (Figure S27). We could thus observe two different coordination modes of alkyneesters $\mathbf{1}-\mathbf{3}$ to $\mathrm{Au}^{\mathrm{I}}$ with $\mathrm{P}_{\mathrm{H}}$ and provide plausible assignments of the coordinating species.

Table 1. Rate constants for the interaction of $\mathrm{Au}^{\mathrm{I}}$-alkyne-esters $\mathbf{1}-\mathbf{3}$ with the $\mathrm{P}_{\mathrm{H}}$ Pore $^{[\mathrm{a}]}$

\begin{tabular}{l|ll|ll|ll}
\hline & \multicolumn{2}{c|}{$\mathbf{1}$} & \multicolumn{2}{c|}{$\mathbf{2}$} & \multicolumn{2}{c}{$\mathbf{3}$} \\
Transition & Rate Constant & $n^{[\mathrm{b}]}$ & Rate Constant & $n^{[\mathrm{b}]}$ & Rate Constant & $n^{[\mathrm{b}]}$ \\
\hline$k_{12}\left(\mathrm{M}^{-1} \mathrm{~s}^{-1}\right)$ & $2.3 \pm 0.2 \times 10^{2}$ & 32 & $2.5 \pm 0.1 \times 10^{2}$ & 35 & $1.6 \pm 0.2 \times 10^{2}$ & 21 \\
$k_{21}\left(\mathrm{~s}^{-1}\right)$ & $4.2 \pm 0.5$ & 40 & $4.0 \pm 0.6$ & 42 & $4.1 \pm 0.2$ & 27 \\
$k_{13}\left(\mathrm{M}^{-1} \mathrm{~s}^{-1}\right)$ & $1.2 \pm 0.1 \times 10^{3}$ & 164 & $1.15 \pm 0.09 \times 10^{3}$ & 193 & $6.2 \pm 1.2 \times 10^{2}$ & 136 \\
$k_{31}\left(\mathrm{~s}^{-1}\right)$ & $10.5 \pm 0.5$ & 163 & $6.4 \pm 0.6$ & 190 & $11.1 \pm 0.8$ & 139 \\
$k_{23}\left(\mathrm{~s}^{-1}\right)$ & $6.4 \pm 0.5$ & 64 & $8.1 \pm 0.4$ & 99 & $6.4 \pm 0.3$ & 47 \\
$k_{32}\left(\mathrm{~s}^{-1}\right)$ & $4.4 \pm 0.4$ & 72 & $2.9 \pm 0.2$ & 104 & $3.0 \pm 0.3$ & 19 \\
\hline
\end{tabular}

[a] Conditions: $2 \mathrm{M} \mathrm{KCl}, 10 \mathrm{mM}$ MES, Chelex, pH 6.1, recorded at $-50 \mathrm{mV}$ and $21 \pm 1{ }^{\circ} \mathrm{C}(n=3)$

[b] $n=$ number of events recorded in a selected experiment when $150 \mu \mathrm{M}$ of both $\mathrm{Au}^{\mathrm{I}}(\mathrm{tcep}) \mathrm{Cl}$ and alkyne ester were added to the trans compartment (refer to Figure 3) 


\section{Gold(I) catalysed cyclisation of acetylenic acids}

The intramolecular cyclisation of acetylenic acids to produce enol lactones is catalysed by $\mathrm{Au}^{\mathrm{I}}$ salts in organic solvent (Figure 1d). ${ }^{23-25}$ It has been proposed that the $\mathrm{Au}^{\mathrm{I}}$ catalyst first coordinates to and activates the alkyne to promote the addition of the nucleophilic carboxylic acid. The corresponding vinyl-Au ${ }^{\mathrm{I}}$ species, which has been isolated and visualised with X-ray crystallography, ${ }^{45-46}$ protodemetallates to yield the product and returns $\mathrm{Au}^{\mathrm{I}}$ to the catalytic cycle. Accordingly, we found that the treatment of 4-pentynoic acid with $\mathrm{Au}^{\mathrm{I}}$ (tcep)Cl at room temperature in water (buffered at $\mathrm{pH} 6.0$, with and without $2 \mathrm{M} \mathrm{KCl}$ ) cleanly produced $\gamma$ methylene- $\gamma$-butyrolactone (Figures S28 and S29); these conditions were used because they were similar to the conditions employed in the nanoreactor experiments. The selective exo-dig cyclisation was also observed in organic media (Figure S30), consistent with literature observations. An exo-lactone was also produced catalytically from the similar acetylenic acid, 2,2dimethyl-4-pentynoic acid, under the same aqueous conditions (Figure S31). As we were able to observe $\mathrm{Au}^{\mathrm{I}}$-alkyne binding to the $\mathrm{P}_{\mathrm{H}}$ pore, we examined the intermediates in the catalytic cyclisation of acetylenic acids at the single-molecule level by using the nanoreactor approach.

When $\mathrm{Au}^{\mathrm{I}}($ tcep$) \mathrm{Cl}(300 \mu \mathrm{M})$ was added to the trans compartment of the bilayer apparatus containing 4-pentynoic acid (300 $\mu \mathrm{M}$; stoichiometric conditions) in $2 \mathrm{M} \mathrm{KCl}, 10 \mathrm{mM} \mathrm{MES}, \mathrm{pH}$ 6.1 , at an applied potential of $-50 \mathrm{mV}$ (Figure $4 \mathrm{a}$ ), we observed three reversible blockades of $\mathrm{P}_{\mathrm{H}}$ in addition to the open pore current (level 1) and the level with $\mathrm{Au}^{\mathrm{I}}$ bound (level 0) (Figure $4 \mathrm{~b}$ and Figures S32 and S33). Because the catalytic reaction proceeds in the trans compartment, $\mathrm{P}_{\mathrm{H}}$ samples and records the intermediate $\mathrm{Au}^{\mathrm{I}}$-ligand species present in solution during the transformation. Transitions linking intermediates are observed as partial reaction cycles that occur on $\mathrm{P}_{\mathrm{H}}$, permitting construction of a reaction cycle and the associated kinetics. Performing the reaction under catalytic conditions $\left(2 \mu \mathrm{M} \mathrm{Au}^{\mathrm{I}}\right.$ (tcep) $\mathrm{Cl}$ and $500 \mu \mathrm{M}$ 4-pentynoic acid) did not yield sufficient binding events of $\mathrm{Au}^{\mathrm{I}}$-ligand intermediate species for statistical analysis. Further, when $30 \mu \mathrm{M}(10 \mathrm{~mol} \%)$ of $\mathrm{Au}^{\mathrm{I}} \mathrm{Cl}_{2}{ }^{-}$was used as the catalyst with $300 \mu \mathrm{M}$ 4-pentynoic acid, although the same reversible blockades were initially observed as seen with $\mathrm{Au}^{\mathrm{I}}(\mathrm{tcep}) \mathrm{Cl}$, the ionic current through the nanopore quickly became blocked (Figure S34). We postulate that in the absence of a phosphine-coordinating ligand, aggregated $\mathrm{Au}^{\mathrm{I}}$ and $\mathrm{Au}^{\mathrm{I}}$-ligand complexes form in solution and block the nanopore. ${ }^{17}$ The three current blockades suggested that there are three different $\mathrm{Au}^{\mathrm{I}}-$ ligand species involved in the catalytic cycle ( $n=5$, independent experiments). We also recorded only three current blockades with the acetylenic acid 2,2-dimethyl-4-pentynoic acid $(n=3)$ (Figures S35 and S36). The largest blockade observed with 4-pentynoic acid (6.9 $\pm 0.3 \mathrm{pA})$ was designated level 4 and had a life-time of $26 \pm 1 \mathrm{~ms}$. Smaller blockades of $5.2 \pm 0.2 \mathrm{pA}$ (level 3) 
and $3.8 \pm 0.2 \mathrm{pA}$ (level 2) had longer life-times of $152 \pm 8 \mathrm{~ms}$ and $205 \pm 8 \mathrm{~ms}$, respectively (Figure $4 \mathrm{~b})$. The number of events at each observed level decreased over the course of the reaction as 4pentynoic acid was converted to the enol lactone. The cumulative plots of the events fitted well to exponential functions, as expected for a decay with a first-order dependence on each intermediate (Figure 4c). As the time-dependence of the derivative of a cumulative events plot reflects the change in concentration of an analyte with time (Supplementary Section 4.1), ${ }^{47}$ and the initial concentration of 4-pentynoic acid was known, we were able to determine a rate constant of $5.7 \pm$ $0.8 \times 10^{-4} \mathrm{~s}^{-1}$ (the three intermediates gave the same rate constant and was averaged over five experiments to determine the overall rate constant). The similar calculated rate constant for the conversion of all of the observed intermediates (levels 4, 3 and 2) suggest that they interconvert at rates considerably faster than the rate of product formation (see below). When the reaction was followed by ${ }^{1} \mathrm{H}$ NMR under the same conditions in buffered $\mathrm{D}_{2} \mathrm{O}(2 \mathrm{M} \mathrm{KCl}, 10 \mathrm{mM}$ MES, $\mathrm{p}(\mathrm{DH})$ 6.1 ), a similar rate constant of $4.3 \pm 0.7 \times 10^{-4} \mathrm{~s}^{-1}$ was obtained. A rate constant of $5.5 \pm 0.5 \times 10^{-4}$ $\mathrm{s}^{-1}$ was determined with 2,2-dimethyl-4-pentynoic acid (Figure S37). 
A

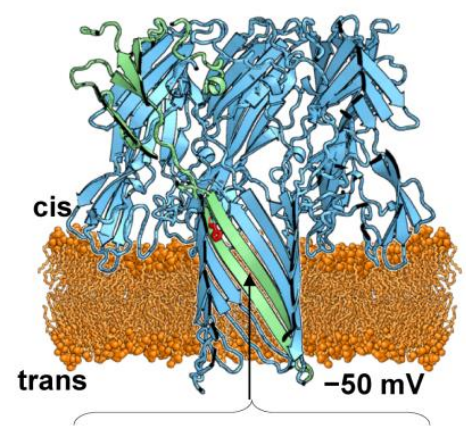

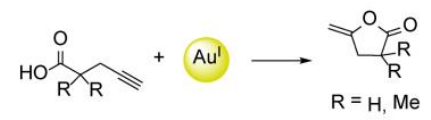

$\mathbf{B}$

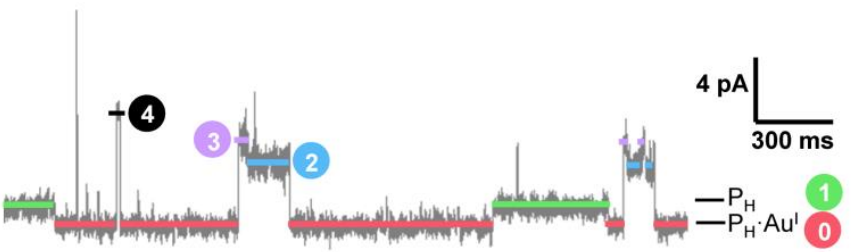

C
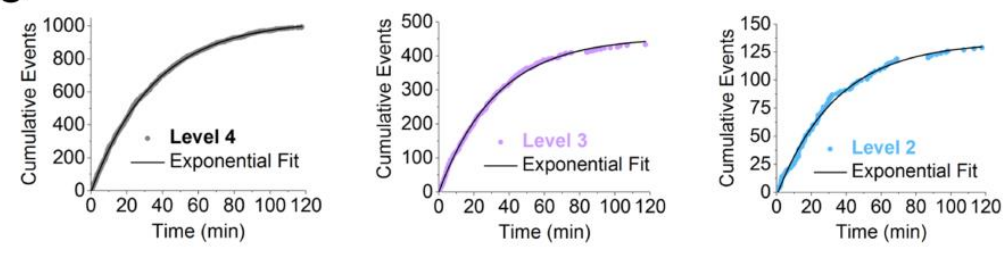

E
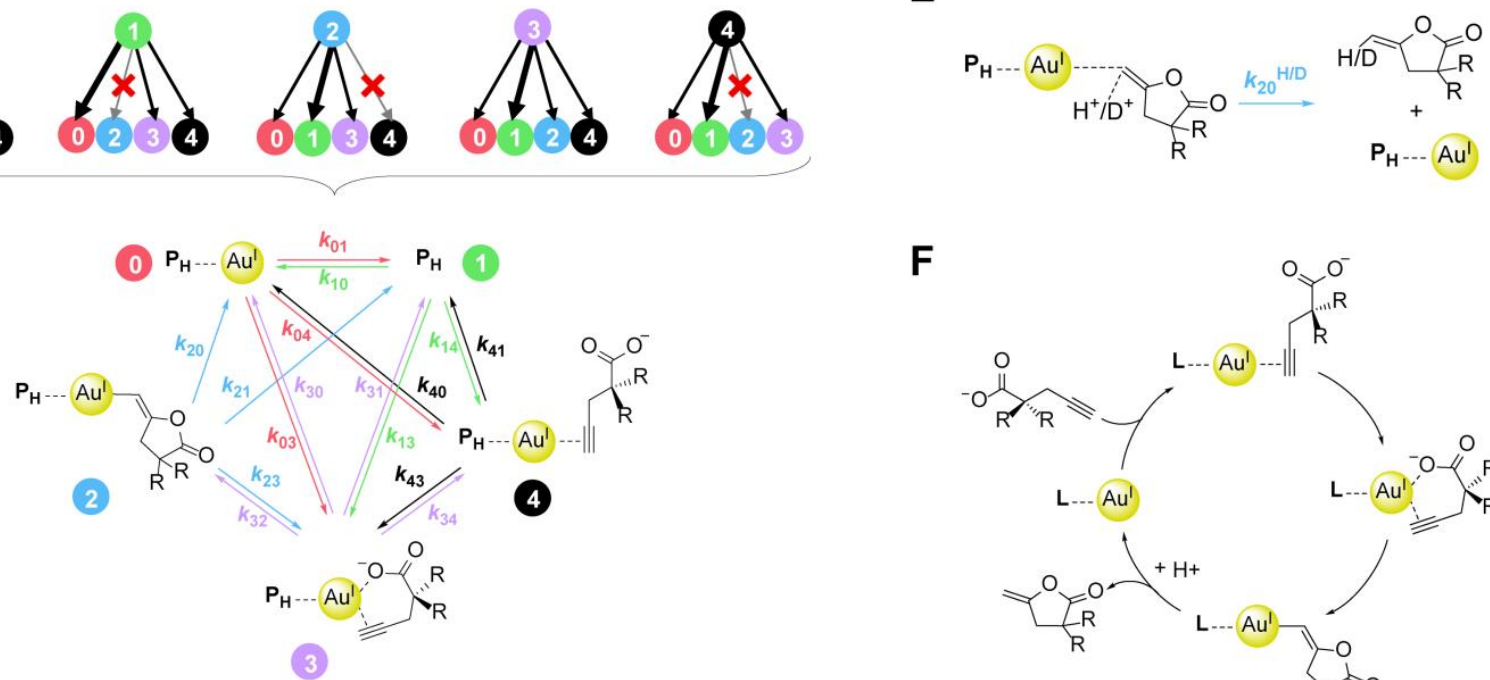

$\mathbf{F}$
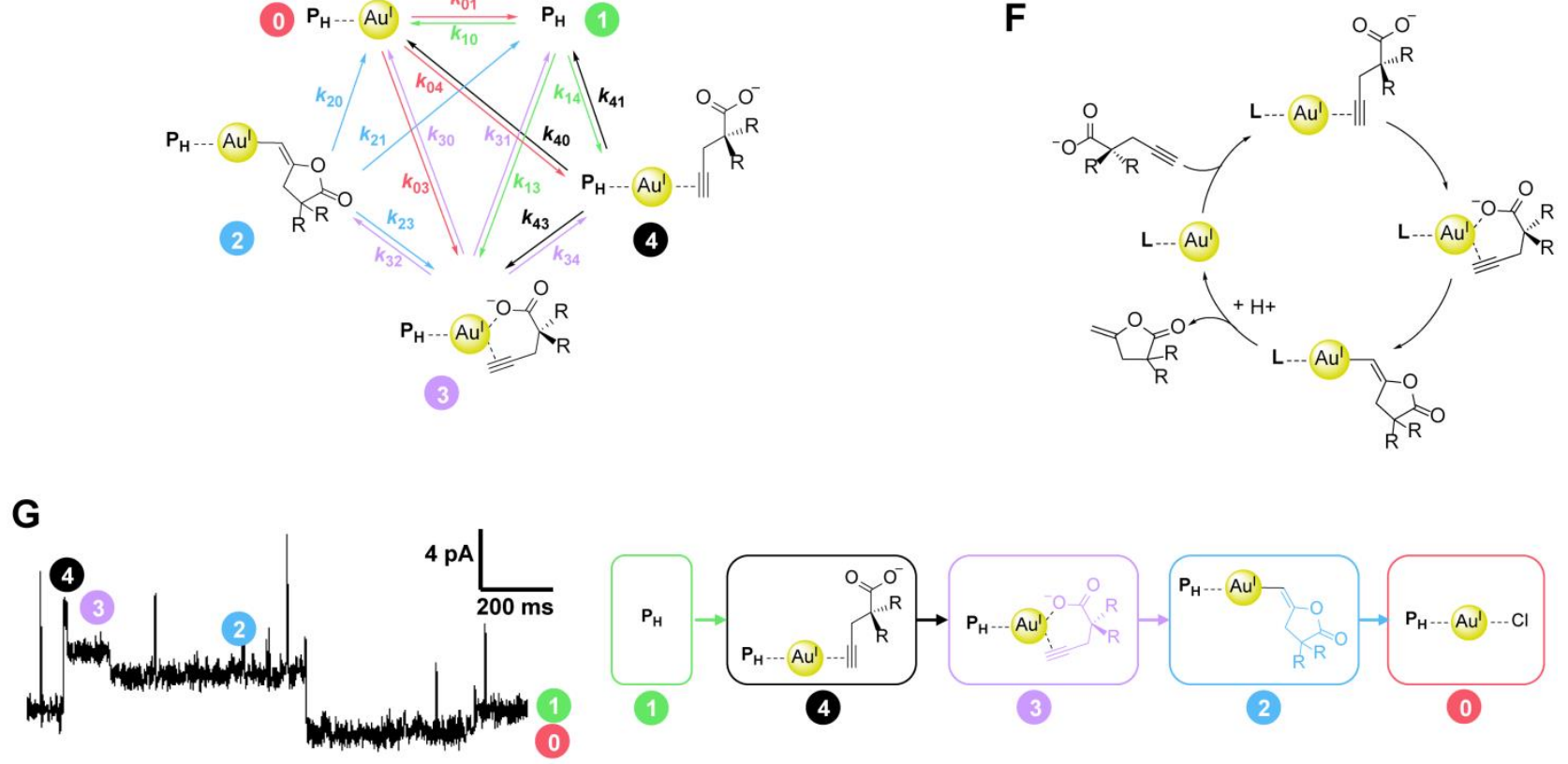

Figure 4. Single-molecule detection of catalytic intermediates. (a) A single $\mathrm{P}_{\mathrm{H}}$ pore was incorporated into a planar lipid bilayer. An acetylenic acid was introduced to the trans compartment and the catalyst, $\mathrm{Au}^{\mathrm{I}}(\mathrm{tcep}) \mathrm{Cl}$, was added to initiate the reaction and catalytically produce the enol lactone. Conditions: $2 \mathrm{M} \mathrm{KCl}, 10 \mathrm{mM} \mathrm{MES}, \mathrm{pH} 6.1,21 \pm 1{ }^{\circ} \mathrm{C}$. (b) At an applied potential of $-50 \mathrm{mV}$, analysis of the electrical recording during the reaction (grey) identified three current blocking events accessed from either the $\mathrm{Au}^{\mathrm{I}}$-bound state (level 0; red) or the unoccupied pore (level 1; green), which were assigned as level 4 (black), level 3 (purple), and level 2 (blue). (c) Cumulative plots of the reaction progress. The number of recorded events is proportional to the concentration of the intermediate $\mathrm{Au}^{\mathrm{I}}$-species and decreases over time as the substrate is converted to the product. (d) The transitions from each level observed in the electrical recordings were analysed to determine accessible transitions. This information was combined to create a kinetic model that describes the transitions between current levels. (e) Proposed kinetic scheme describing the protonmediated demetallation step $\left(k_{20}\right)$. (f) Our proposed catalytic cycle that describes the $\mathrm{Au}^{\mathrm{I}}$-catalysed cyclisation of acetylenic acids. (g) A recording of a complete catalytic cycle for the transformation of 4-pentynoic acid within $\mathrm{P}_{\mathrm{H}}$ that transitions from levels $1 \rightarrow 4 \rightarrow 3 \rightarrow 2 \rightarrow 0$. The chemical structure proposed for each level is shown.

We analysed the transitions from each level during the reaction of either 4-pentynoic acid or 2,2-dimethyl-4-pentynoic acid with $\mathrm{Au}^{\mathrm{I}}$ (Figure 4d, top). We observed reversible transitions from 
the $\mathrm{Au}^{\mathrm{I}}$-bound state (level 0) to level 1 (open pore), level 3 and 4. Similarly, reversible transitions were observed from the open pore (level 1) to levels 0,3 and 4 . We also found that several pathways were rarely observed ( $\leq 2 \%$ of the total transitions from that level): transitions from either the open pore (level 1) or the $\mathrm{Au}^{\mathrm{I}}$-bound state (level 0) to level 2, and transitions between levels 2 and 4. This revealed that level 2 was accessed predominantly from level 3. We collated this information to construct a five-state model that describes these transitions (Figure 4d, bottom). The rate constants associated with the transitions were determined by Hidden Markov modelling (QUB 2.0, Buffalo University) (Table 2). Control experiments involving the addition of $\mathrm{Au}^{\mathrm{I}}(\mathrm{tcep}) \mathrm{Cl}$ and excess enol lactone to the trans compartment under the same conditions revealed that the enol lactone product of the catalytic reaction did not coordinate to $\mathrm{Au}^{\mathrm{I}}$ (Figure S38). As we also observed that level 2 does not occur from the coordination of a ligand, this suggested that level 2 may be assigned to the vinyl-Au ${ }^{\mathrm{I}}$ complex, which is the last intermediate in the proposed catalytic cycle (Figure 1d). To better support this assignment, and as the vinyl-Au ${ }^{\mathrm{I}}$ species protodemetallates to release the enol lactone and reintroduce $\mathrm{Au}^{\mathrm{I}}$ into the catalytic cycle (Figure $4 \mathrm{e})$, we repeated the reaction with 4-pentynoic and $\mathrm{Au}^{\mathrm{I}}$ in $\mathrm{D}_{2} \mathrm{O}$ solution $(n=3$, independent experiments) (Figures S39 and S40). We determined a rate constant of $3.8 \pm 1.3 \times 10^{-4} \mathrm{~s}^{-1}$ (using $300 \mu \mathrm{M}$ of both 4-pentynoic acid and $\mathrm{Au}^{\mathrm{I}}(\mathrm{tcep}) \mathrm{Cl}$; Figure S41), slower than that observed in $\mathrm{H}_{2} \mathrm{O}$ $\left(5.7 \pm 0.8 \times 10^{-4} \mathrm{~s}^{-1}\right.$, performed with the same reactant concentrations) and consistent with ${ }^{1} \mathrm{H}$ NMR spectroscopy experiments in $\mathrm{D}_{2} \mathrm{O}\left(4.3 \pm 0.7 \times 10^{-4} \mathrm{~s}^{-1}\right)$; we also extrapolated a product formation rate constant of $\sim 7 \times 10^{-4} \mathrm{~s}^{-1}$ from individual rate constants (Supplementary Section 4.3), which agrees (roughly) with the bulk-observed rate constant. We found a small solvent kinetic hydrogen-deuterium isotope effect ${ }^{48-50}$ in the transition from level 2 to level $0, k_{20}{ }^{\mathrm{H}} / k_{20}{ }^{\mathrm{D}}=1.7$ (Table 2), and determined statistically insignificant $(P<0.05)$ isotope effects in the transitions from level 4 and level 3 to level $0\left(k_{40} \mathrm{H} / k_{40} \mathrm{D}=1.2\right.$ and $\left.k_{30} \mathrm{H} / k_{30} \mathrm{D}=1.1\right)$. This unambiguously establishes that the transition from level 2 to level 0 is a proton mediated step, consistent with our assignment of level 2 to the vinyl-Au ${ }^{\mathrm{I}}$ species, which requires protonation for the product to dissociate from the $\mathrm{Au}^{\mathrm{I}}$ center. We also observed solvent kinetic isotope effects of $<1$ for transitions to the open pore $\left(k_{01}, k_{21}, k_{31}\right.$, and $\left.k_{41}\right)$, coincident with isotope effects of $>1$ for transitions from the open pore $\left(k_{10}, k_{13}\right.$ and $\left.k_{14}\right)$ (Table 2). We postulate that these solvent isotope effects result from the difference in hydrogen bond strength between $\mathrm{H}_{2} \mathrm{O}$ and $\mathrm{D}_{2} \mathrm{O}$ to the His-145 coordinating group. ${ }^{51}$ 
Table 2. Rate constants for the steps involved in the $\mathrm{Au}^{\mathrm{I}}$-catalysed conversion of of acetylenic acids to enol lactones as determined with the $\mathrm{P}_{\mathrm{H}}$ pore

\begin{tabular}{l|ll|ll|l|ll}
\hline & \multicolumn{5}{|c|}{ 4-pentynoic acid } & \multicolumn{2}{c}{ 2,2-dimethyl-4-pentynoic } \\
acid & & \multicolumn{2}{c}{} \\
Transition & $\mathrm{H}_{2} \mathrm{O}^{[\mathrm{a}]}(n=5)$ & $n^{[\mathrm{b}]}$ & $\mathrm{D}_{2} \mathrm{O}^{[\mathrm{c}]}(n=3)$ & $n^{[\mathrm{b}]}$ & $k^{\mathrm{H}} / k^{\mathrm{D}}$ & $\mathrm{H}_{2} \mathrm{O}^{[\mathrm{a}]}(n=3)$ & $n^{[\mathrm{b}]}$ \\
\hline$k_{01}\left(\mathrm{~s}^{-1}\right)$ & $1.5 \pm 0.3$ & 4137 & $3.9 \pm 0.4$ & 1899 & $0.40 \pm 0.09$ & $1.2 \pm 0.2$ & 4260 \\
$k_{03}\left(\mathrm{M}^{-1} \mathrm{~s}^{-1}\right)$ & $1.0 \pm 0.2 \times 10^{3}$ & 190 & $1.3 \pm 0.4 \times 10^{3}$ & 99 & $0.83 \pm 0.31$ & $1.2 \pm 0.2 \times 10^{3}$ & 296 \\
$k_{04}\left(\mathrm{M}^{-1} \mathrm{~s}^{-1}\right)$ & $5.8 \pm 1.7 \times 10^{2}$ & 120 & $4.3 \pm 1.8 \times 10^{2}$ & 31 & $1.33 \pm 0.66$ & $7.4 \pm 0.3 \times 10^{2}$ & 130 \\
$k_{10}\left(\mathrm{M}^{-1} \mathrm{~s}^{-1}\right)$ & $2.8 \pm 0.8 \times 10^{3}$ & 4127 & $8.7 \pm 1.2 \times 10^{2}$ & 1899 & $3.25 \pm 1.11$ & $2.9 \pm 0.1 \times 10^{3}$ & 4276 \\
$k_{13}\left(\mathrm{M}^{-1} \mathrm{~s}^{-1}\right)$ & $6.4 \pm 2.5 \times 10^{2}$ & 154 & $4.1 \pm 0.9 \times 10^{2}$ & 225 & $1.55 \pm 0.71$ & $7.6 \pm 1.7 \times 10^{3}$ & 174 \\
$k_{14}\left(\mathrm{M}^{-1} \mathrm{~s}^{-1}\right)$ & $1.6 \pm 0.5 \times 10^{3}$ & 825 & $1.5 \pm 0.5 \times 10^{3}$ & 1022 & $1.08 \pm 0.47$ & $1.8 \pm 0.6 \times 10^{3}$ & 798 \\
$k_{20}\left(\mathrm{~s}^{-1}\right)$ & $0.8 \pm 0.2$ & 22 & $0.5 \pm 0.1$ & 10 & $1.73 \pm 0.55$ & $0.7 \pm 0.1$ & 24 \\
$k_{21}\left(\mathrm{~s}^{-1}\right)$ & $1.9 \pm 0.7$ & 52 & $4.2 \pm 0.4$ & 55 & $0.46 \pm 0.17$ & $1.8 \pm 0.2$ & 29 \\
$k_{23}\left(\mathrm{~s}^{-1}\right)$ & $1.0 \pm 0.3$ & 34 & $1.1 \pm 0.1$ & 13 & $0.85 \pm 0.25$ & $1.4 \pm 0.2$ & 51 \\
$k_{30}\left(\mathrm{~s}^{-1}\right)$ & $1.6 \pm 0.4$ & 156 & $1.5 \pm 0.4$ & 94 & $1.09 \pm 0.41$ & $1.7 \pm 0.2$ & 281 \\
$k_{31}\left(\mathrm{~s}^{-1}\right)$ & $3.0 \pm 0.5$ & 199 & $4.7 \pm 0.3$ & 230 & $0.64 \pm 0.12$ & $2.6 \pm 0.3$ & 182 \\
$k_{32}\left(\mathrm{~s}^{-1}\right)$ & $1.6 \pm 0.5$ & 25 & $1.5 \pm 0.2$ & 20 & $1.08 \pm 0.40$ & $1.8 \pm 0.2$ & 41 \\
$k_{34}\left(\mathrm{~s}^{-1}\right)$ & $0.5 \pm 0.3$ & 31 & $0.59 \pm 0.09$ & 27 & $0.83 \pm 0.47$ & $1.4 \pm 0.2$ & 124 \\
$k_{40}\left(\mathrm{~s}^{-1}\right)$ & $1.1 \pm 0.2$ & 130 & $0.9 \pm 0.3$ & 80 & $1.17 \pm 0.44$ & $1.9 \pm 0.7$ & 131 \\
$k_{41}\left(\mathrm{~s}^{-1}\right)$ & $26.4 \pm 5.6$ & 817 & $35.8 \pm 2.4$ & 1025 & $0.74 \pm 0.16$ & $25.2 \pm 0.4$ \\
$k_{43}\left(\mathrm{~s}^{-1}\right)$ & $1.1 \pm 0.4$ & 31 & $1.2 \pm 0.4$ & 29 & $0.86 \pm 0.43$ & $3.5 \pm 0.3$ & 812 \\
\hline
\end{tabular}

[a] Conditions: $2 \mathrm{M} \mathrm{KCl}, 10 \mathrm{mM}$ MES, Chelex, pH 6.1, recorded at $-50 \mathrm{mV}$ and $21 \pm 1{ }^{\circ} \mathrm{C}$

[b] $n=$ number of events recorded in a selected experiment when $300 \mu \mathrm{M}$ of both $\mathrm{Au}^{\mathrm{I}}$ (tcep) $\mathrm{Cl}$ and acetylenic acid were added to the trans compartment (refer to Figure 4)

[c] Conditions: $2 \mathrm{M} \mathrm{KCl}, 10 \mathrm{mM}$ MES, Chelex, $\mathrm{p}(\mathrm{DH}) 6.1$, recorded at $-50 \mathrm{mV}$ and $21 \pm 1{ }^{\circ} \mathrm{C}$

The life-times $\left(\tau_{\text {off }}\right)$ and amplitudes of levels 4 and 3 observed during the catalytic cycle were similar to the life-times of the binding events established with the unreactive alkyne-esters. We therefore assigned level 4 in the catalytic cycle to the $\mathrm{Au}^{\mathrm{I}}$-alkyne $\pi$-complex and level 3 to the formation of the alkyne-acid chelate (Figure 4d). We propose a catalytic cycle for the cyclisation of acetylenic acids in accord with our observations at the single-molecule level (Figure 4f). In the first step, the substrate coordinates to an open site on $\mathrm{Au}^{\mathrm{I}}$ through the alkyne group to form a linear complex, activating the alkyne for nucleophilic attack. The $\mathrm{Au}^{\mathrm{I}}$ center must then position the carboxylic acid to attack the activated alkyne. The resultant vinyl-Au ${ }^{\mathrm{I}}$ species is then protonated to release the enol lactone irreversibly and allow $\mathrm{Au}^{\mathrm{I}}$ to continue in the catalytic cycle. Although the identity of the catalytic intermediates cannot be proven definitively with our nanopore sensing approach, our catalytic model is the simplest and most chemically plausible scenario to describe the single-molecule experiments. Our strategy for the observation of catalysis at the singlemolecule level relies on sampling the reaction as it proceeds in solution, observing the rates of transitions within the pore, and compiling this information to construct a catalytic cycle. We observed only a single event during a two hour electrical recording with 4-pentynoic acid that showed a sequence corresponding to a complete catalytic cycle without dissociation from the nanoreactor (i.e. levels 4 to 3 to 2 to 0 ) (Figure $4 \mathrm{~g}$ ). This is consistent with an expectation based on the probabilities of the different transitions (Supplementary Section 4.4). Furthermore, the observation of the transitions from levels 4 and 3 ( $\mathrm{Au}^{\mathrm{I}}$-alkyne intermediate species) to level 0 (the 
$\mathrm{Au}^{\mathrm{I}}$-bound state) indicate that a substrate can dissociate from the catalytic $\mathrm{Au}^{\mathrm{I}}$ center before irreversible production of the enol lactone.

\section{CONCLUSIONS}

In this study, we have monitored the $\mathrm{Au}^{\mathrm{I}}$-catalysed transformation of acetylenic acids into enol lactones in real time, observing transitions at the single-molecule level and thereby establishing the intermediates in the catalytic cycle. The nanoreactor approach has allowed direct observation of the individual reaction intermediates and an analysis of the lifetimes and the allowed transitions of each species. Therefore, the approach has advantages over ensemble measurements, which are often limited to monitoring the rate-determining step. Although our approach is limited to the investigation of reactions that occur in water, aqueous metal-catalysed reactions are of increasing importance in bio-orthogonal and green chemistry. As we have been able to discriminate between enantiomeric amino acids by binding to a copper(II) complex within a nanopore, ${ }^{47}$ we believe our approach may be adapted to identify the handedness of a chiral intermediate involved in a metalcatalysed reaction. We anticipate that the observation of the reactions of ligands on catalytically active metal centres bound within a nanopore will shed light on additional multistep reaction mechanisms.

\section{ASSOCIATED CONTENT}

\section{Supporting Information}

The Supporting Information for this paper is available free of charge on the ACS Publications website.

Synthetic details, characterisation data, and single-molecule analyses.

\section{AUTHOR INFORMATION}

\section{Corresponding Author}

*E-mail: hagan.bayley@chem.ox.ac.uk

\section{ORCID}

Hagan Bayley : 0000-0003-2499-6116

\section{Notes}

The authors declare no competing financial interest. 


\section{ACKNOWLEDGEMENTS}

This work was supported by a European Research Council Advanced Grant (COSIMO). Y.Q. was the recipient of China Scholarship Council-University of Oxford Scholarship.

\section{REFERENCES}

1. Magano, J.; Dunetz, J. R., Large-scale applications of transition metal-catalyzed couplings for the synthesis of pharmaceuticals. Chem. Rev. 2011, 111 (3), 2177-2250.

2. Beller, M.; Blaser, H. U.; Eds., Organometallics as Catalysts in the Fine Chemical Industry, vol 42 of Topics in Organometallic Chemistry. Springer, Berlin, Heidelberg: 2012.

3. Topczewski, J. J.; Cabrera, P. J.; Saper, N. I.; Sanford, M. S., Palladium-catalysed transannular C-H functionalization of alicyclic amines. Nature 2016, 531 (7593), 220-224.

4. Thomas, A. A.; Denmark, S. E., Pre-transmetalation intermediates in the Suzuki-Miyaura reaction revealed: the missing link. Science 2016, 352 (6283), 329-332.

5. Zhang, M.; Frei, H., Water Oxidation Mechanisms of Metal Oxide Catalysts by Vibrational Spectroscopy of Transient Intermediates. Annu. Rev. Phys. Chem. 2017, 68 (1), 209-231.

6. Malta, G.; Kondrat, S. A.; Freakley, S. J.; Davies, C. J.; Lu, L.; Dawson, S.; Thetford, A.; Gibson, E. K.; Morgan, D. J.; Jones, W.; Wells, P. P.; Johnston, P.; Catlow, C. R. A.; Kiely, C. J.; Hutchings, G. J., Identification of single-site gold catalysis in acetylene hydrochlorination. Science 2017, 355 (6332), 1399-1403.

7. Attar, A. R.; Bhattacherjee, A.; Pemmaraju, C. D.; Schnorr, K.; Closser, K. D.; Prendergast, D.; Leone, S. R., Femtosecond $\mathrm{x}$-ray spectroscopy of an electrocyclic ring-opening reaction. Science 2017, 356 (6333), 54-59.

8. Schuler, B.; Fatayer, S.; Mohn, F.; Moll, N.; Pavliček, N.; Meyer, G.; Peña, D.; Gross, L., Reversible Bergman cyclization by atomic manipulation. Nat. Chem. 2016, 8 (3), 220-224.

9. Riss, A.; Paz, A. P.; Wickenburg, S.; Tsai, H.-Z.; De Oteyza, D. G.; Bradley, A. J.; Ugeda, M. M.; Gorman, P.; Jung, H. S.; Crommie, M. F.; Rubio, A.; Fischer, F. R., Imaging single-molecule reaction intermediates stabilized by surface dissipation and entropy. Nat. Chem. 2016, 8, 678 .

10. van Schrojenstein Lantman, E. M.; Deckert-Gaudig, T.; Mank, A. J. G.; Deckert, V.; Weckhuysen, B. M., Catalytic processes monitored at the nanoscale with tip-enhanced Raman spectroscopy. Nat. Nanotech. 2012, 7, 583.

11. Arina, R.; Carolin, L.; Marcel, W.; Kristin, G. m.; Anton, K.; Frank, M.; Alexander, S.; Oliver, T.; Gregor, J.; Dirk-Peter, H., Distinguishing Alternative Reaction Pathways by Single-Molecule Fluorescence Spectroscopy. Angew. Chem. Int. Ed. 2013, 52 (24), 6322-6325.

12. Ng, J. D.; Upadhyay, S. P.; Marquard, A. N.; Lupo, K. M.; Hinton, D. A.; Padilla, N. A.; Bates, D. M.; Goldsmith, R. H., Single-molecule investigation of initiation dynamics of an organometallic catalyst. J. Am. Chem. Soc. 2016, 138 (11), 3876-3883.

13. Liu, C.; Kubo, K.; Wang, E.; Han, K.-S.; Yang, F.; Chen, G.; Escobedo, F. A.; Coates, G. W.; Chen, P., Single polymer growth dynamics. Science 2017, 358 (6361), 352-355.

14. Easter, Q. T.; Blum, S. A., Single Turnover at Molecular Polymerization Catalysts Reveals Spatiotemporally Resolved Reactions. Angew. Chem. Int. Ed. 2017, 56 (44), 13772-13775.

15. Song, L.; Hobaugh, M. R.; Shustak, C.; Cheley, S.; Bayley, H.; Gouaux, J. E., Structure of Staphylococcal $\alpha$-Hemolysin, a Heptameric Transmembrane Pore. Science 1996, 274 (5294), 1859-1865.

16. Bayley, H.; Luchian, T.; Shin, S. H.; Steffensen, M. B., "Single-molecule covalent chemistry in a protein nanoreactor" in Single Molecules and Nanotechnology (Eds Rigler, R.; Vogel, H.) Springer: 2008, 251-277. 
17. Choi, L.-S.; Mach, T.; Bayley, H., Rates and stoichiometries of metal ion probes of cysteine residues within ion channels. Biophys. J. 2013, 105 (2), 356-364.

18. Boersma, A. J.; Brain, K. L.; Bayley, H., Real-time stochastic detection of multiple neurotransmitters with a protein nanopore. ACS Nano 2012, 6 (6), 5304-5308.

19. Lu, S.; Li, W.-W.; Rotem, D.; Mikhailova, E.; Bayley, H., A primary hydrogen-deuterium isotope effect observed at the single-molecule level. Nat. Chem. 2010, 2 (11), 921-928.

20. Ren, H.; Cheyne, C. G.; Fleming, A. M.; Burrows, C. J.; White, H. S., Single-Molecule Titration in a Protein Nanoreactor Reveals the Protonation/Deprotonation Mechanism of a C:C Mismatch in DNA. J. Am. Chem. Soc. 2018, 140 (15), 5153-5160.

21. Lee, J.; Bayley, H., Semisynthetic protein nanoreactor for single-molecule chemistry. Proc. Natl. Acad. Sci. U.S.A. 2015, 112 (45), 13768-13773.

22. Pulcu, G. S.; Mikhailova, E.; Choi, L.-S.; Bayley, H., Continuous observation of the stochastic motion of an individual small-molecule walker. Nat. Nanotech. 2015, 10 (1), 76-83.

23. Genin, E.; Toullec, P. Y.; Antoniotti, S.; Brancour, C.; Genêt, J.-P.; Michelet, V., Room temperature $\mathrm{Au}(\mathrm{I})$-catalyzed exo-selective cycloisomerization of acetylenic acids: an entry to functionalized $\gamma$-lactones. J. Am. Chem. Soc. 2006, 128 (10), 3112-3113.

24. Harkat, H.; Dembelé, A. Y.; Weibel, J.-M.; Blanc, A.; Pale, P., Cyclization of alkynoic acids with gold catalysts: a surprising dichotomy between $\mathrm{Au}^{\mathrm{I}}$ and $\mathrm{Au}^{\mathrm{III}}$. Tetrahedron 2009, 65 (9), 1871-1879.

25. Jimenez-Nunez, E.; Echavarren, A. M., Molecular diversity through gold catalysis with alkynes. Chem. Comm. 2007, (4), 333-346.

26. Maglia, G.; Restrepo, M. R.; Mikhailova, E.; Bayley, H., Enhanced translocation of single DNA molecules through $\alpha$-hemolysin nanopores by manipulation of internal charge. Proc. Natl. Acad. Sci. U.S.A. 2008, 105 (50), 19720-19725.

27. Pan, P.; Wood, S. A., Gold-chloride complexes in very acidic aqueous solutions and at temperatures $25-300{ }^{\circ} \mathrm{C}$ : A laser Raman spectroscopic study. Geochim. Cosmochim. Acta 1991, 55 (8), 2365-2371.

28. Gammons, C. H.; Yu, Y.; Williams-Jones, A. E., The disproportionation of gold(I) chloride complexes at 25 to $200^{\circ} \mathrm{C}$. Geochim. Cosmochim. Acta 1997, 61 (10), 1971-1983.

29. Hashmi, A. S. K.; Hutchings, G. J., Gold catalysis. Angew. Chem. Int. Ed. 2006, 45 (47), 7896-7936.

30. Widenhoefer, R. A.; Han, X., Gold-catalyzed hydroamination of C-C multiple bonds. Eur. J. Org. Chem. 2006, 2006 (20), 4555-4563.

31. Zhang, L.; Sun, J.; Kozmin, S. A., Gold and platinum catalysis of enyne cycloisomerization. Adv. Synth. Catal. 2006, 348 (16-17), 2271-2296.

32. Jones, P. G.; Williams, A. F., Structure and bonding in gold(I) compounds. Part 1. The trans influence in linear complexes. J. Chem. Soc., Dalton Trans. 1977, (15), 1430-1434.

33. Shapiro, N. D.; Toste, F. D., Synthesis and structural characterization of isolable phosphine coinage metal $\pi$-complexes. Proc. Natl. Acad. Sci. U.S.A. 2008, 105 (8), 2779-2782.

34. Flügge, S.; Anoop, A.; Goddard, R.; Thiel, W.; Fürstner, A., Structure and bonding in neutral and cationic 14-electron gold alkyne $\pi$ complexes. Chem. Eur. J. 2009, 15 (34), 8558-8565.

35. Liu, L.-P.; Hammond, G. B., Recent advances in the isolation and reactivity of organogold complexes. Chem. Soc. Rev. 2012, 41 (8), 3129-3139.

36. Goodwin, J. A.; Aponick, A., Regioselectivity in the Au-catalyzed hydration and hydroalkoxylation of alkynes. Chem. Comm. 2015, 51 (42), 8730-8741.

37. Corma, A.; Leyva-Pérez, A.; Sabater, M. J., Gold-catalyzed carbon-heteroatom bond-forming reactions. Chem. Rev. 2011, 111 (3), 1657-1712.

38. Brooner, R. E. M.; Widenhoefer, R. A., Cationic, Two-Coordinate Gold $\pi$ Complexes. Angew. Chem. Int. Ed. 2013, 52 (45), 11714-11724.

39. Gimeno, M. C.; Laguna, A., Three- and four-coordinate gold(I) complexes. Chem. Rev. 1997, $97(3), 511-522$. 
40. Johnson, A.; Gimeno, M. C., Synthesis of Propargyl-Functionalized NHC Gold Complexes. Organometallics 2017, 36 (7), 1278-1286.

41. Luca, R.; Julio, F.-C.; Gabriele, A.; Isabelle, C.; M., B. P. H.; Manfred, B., Gold(III) Alkyne Complexes: Bonding and Reaction Pathways. Angew. Chem. Int. Ed. 2017, 56 (44), 13861-13865.

42. Romeo, R.; Lanza, S.; Tobe, M. L., Kinetics of the chelate effect. Ring closing and ring opening in cis-dichloro(dimethyl sulfoxido)(2-aminoethylammonium)platinum(II) chloride. Inorg. Chem. 1977, 16 (4), 785-790.

43. Dugave, C.; Demange, L., Cis-trans isomerization of organic molecules and biomolecules: implications and applications. Chem. Rev. 2003, 103 (7), 2475-2532.

44. Pawar, D. M.; Khalil, A. A.; Hooks, D. R.; Collins, K.; Elliott, T.; Stafford, J.; Smith, L.; Noe, E. A., E and Z conformations of esters, thiol esters, and amides. J. Am. Chem. Soc. 1998, 120 (9), 2108-2112.

45. Hashmi, A. S. K.; Ramamurthi, T. D.; Rominger, F., On the trapping of vinylgold intermediates. Adv. Synth. Catal. 2010, 352 (6), 971-975.

46. Egorova, O. A.; Seo, H.; Kim, Y.; Moon, D.; Rhee, Y. M.; Ahn, K. H., Characterization of vinylgold intermediates: gold-mediated cyclization of acetylenic amides. Angew. Chem. Int. Ed. 2011, 50 (48), 11446-11450.

47. Boersma, A. J.; Bayley, H., Continuous stochastic detection of amino acid enantiomers with a protein nanopore. Angew. Chem. Int. Ed. 2012, 51 (38), 9606-9609.

48. Gandour, R. D.; Pivert, M. A.; Kelley, E. L.; Minor, B. D.; Spencer, R.; Ingraham, R. H.; Spindler, S. J., Solvent isotope effects in intramolecular catalysis: acyl transfer reactions of 4nitrophenyl 5-nitrosalicylate in aqueous tris buffer. Bioorg. Chem. 1979, 8 (1), 45-58.

49. Sim, Y.-L.; Ariffin, A.; Khan, M. N., Kinetics and mechanism of large rate enhancement in the alkaline hydrolysis of $\mathrm{N}^{\prime}$-morpholino-N-(2'-methoxyphenyl)phthalamide. J. Org. Chem. 2008, 73 (10), 3730-3737.

50. Belafdal, O.; Bergon, M.; Calmon, M.; Calmon, J. P., Kinetics and mechanisms of cyclization in acidic media of $\mathrm{N}$-[(3,5-dichloroanilino)carbonyl]-N-[(isopropylamino)carbonyl]glycine to hydantoins: iprodione and its isomer. J. Org. Chem. 1989, 54 (17), 4193-4198.

51. Soper, A. K.; Benmore, C. J., Quantum differences between heavy and light water. Phys. Rev. Lett. 2008, 101 (6), 065502.

\section{Table of Contents Graphic}

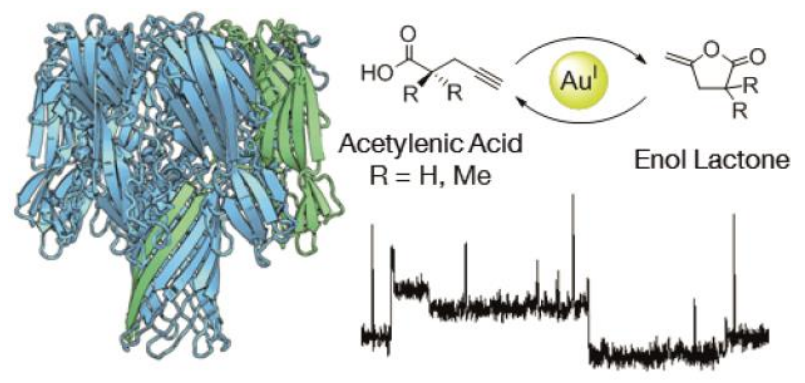

